\title{
Brazilian elderly affective disorders and suicide: trends on morbi-mortality and health service costs
}

\begin{abstract}
Affective disorders (AD), including depression have important epidemiological impact on elderly morbi-mortality been also associated to elevate suicide rates. However, AD impact on trends elderly mortality, morbidity and Brazilian health service cost (hospitalization and outpatient care) need to be more deeply investigated. Therefore, this study evaluated the trends of AD and suicide mortality in Brazilian elderly population (1996-2015) and in use of health services (hospitalization and outpatient care) and their costs in 2009 to 2015 period by a socio-ecological analysis using databank evaluable for Health Unic System (DATASUS, Brazil Ministry). The study was performed just in elderly subjects ( $\geq$ 60 years old) considering as co-variables: sex ad age. Linear, Joint point and multivariate regressions were used to detect change in the trends of $\mathrm{AD}$ and suicide mortality. Total $\mathrm{AD}$ mortality was slightly higher in women (1.2/100.000) than men (1.0/100.000). At contrary, suicide mortality rate was higher in men (13.5/100.000) than females $(2.5 / 100.000)$. In both mortality causes, occurrence was age-dependent, with higher rates in oldest-old group ( $\geq 80$ years). Hospitalizations by $\mathrm{AD}$ was also higher in older group, in both sex. However, hospitalization costs trend to decrease in the last four years. The whole of results suggests the necessity to construct specific preventive and treatment programs for elderly people, since this population presents important biological, functional, health and social specificities that are different of find in adults.
\end{abstract}

Keywords: aging population, depression, mental health, mortality, hospitalization, health service costs
Volume 3 Issue I - 2018

\author{
Raquel de Souza Praia,' Jorge Reboredo, ${ }^{2}$ \\ Fernanda Barbisan,' Ivo Emilio da Cruz \\ Jung, ${ }^{3}$ Pedro Antonio Smith do Prado-Lima, ${ }^{4}$ \\ Moisés Henrique Mastella,' Ednea Aguiar \\ Maia Ribeiro, ${ }^{5}$ Euler Esteves Ribeiro, ${ }^{5}$ Ivana \\ Beatrice Mânica da Cruz ${ }^{1,3}$ \\ 'Graduate Program in Gerontology, Federal University of Santa \\ Maria, Brazil \\ ${ }^{2}$ Universidad de Ciencias Empresariales e Sociales, Argentina \\ ${ }^{3}$ Graduate Program of Pharmacology, Federal University of \\ Santa Maria, Brazil \\ ${ }^{4}$ Brain Institute, Pontifical Catholic University of Rio Grande do \\ Sul, Brazil \\ ${ }^{5}$ Open University of the Third Age, State University of \\ Amazonas, Brazil
}

Correspondence: Ivana BM da Cruz, Graduate Program in Gerontology, Federal University of Santa Maria, Brazil, Zip Code: 97105900, Tel +55-55-99। 199099, Email ibmcruz@hotmail.com

Received: January 26, 2018 | Published: February 26, 2018
Abbreviations: AD, affective disorders; BPR, brazilian psychiatric reform; ICD-10, - international code of diseases; SUS, single health system; SIM, brazilian mortality information.

\section{Introduction}

Mental disorders, affect about 350 million people worldwide representing approximately $12 \%$ of total diseases. ${ }^{1}$ Due their characteristics, in general population, psychiatric disorders are associated with a strong presence of epidemiological panorama, since can interact, aggravate, or even constitute independent risk factor for several types of non-transmissible diseases, such as cardiovascular diseases. ${ }^{2-4}$ In elderly population, affective disorders (AD), especially depression is often undetected and inadequately treated. ${ }^{5}$

Furthermore, despite depression to presents similar symptom between elderly and younger populations is more common the occurrence of other concomitant medical disorders and cognitive impairment. ${ }^{5}$ Therefore, in elderly, close association between $\mathrm{AD}$ and other organic diseases elevate the use of health services (hospitalization and outpatient cares), decreasing patient's life quality and increasing mortality prevalence for direct or indirect mental health causes, including suicide. ${ }^{6}$
For this reason, elderly AD could be considered a strategic point in the clinical and social management of geriatric patient. It is not an easy task, mainly considering middle-income countries, such as Brazil that have experienced a rapid increase in their proportion of elderly people ( $\geq 60$ years old). In this country, the protection and rights of people with mental disorders are regulated by a law known as the Brazilian Psychiatric Reform (BPR), by Psychological Care Network inserted in the Single Health System (Sistema Único de Saúde, SUS), that is a Brazilian universal free healthcare system for all population. This network organizes all SUS services related to mental care treatments including 1) primary care, 2) accident and emergency care, 3) psychosocial care, 4) hospital and ambulatory specialized care, and 5) health surveillance. ${ }^{7}$

Despite advances in Brazilian mental illness care BPR associated, there is necessity to evaluate if general mental health services could impact positively in elderly population, or there is necessity to consider differential structuration of mental health services to attend clinical and social specificities of the elderly population. Based in this context, the present study evaluated trends of mortality of elderly ADdiagnosed or who committed suicide from 1996 to 2015, and also morbidity (hospitalization and outpatient care) and Brazilian health service cost related to elderly AD-diagnosed. 


\section{Materials and methods}

\section{Study design}

A socio-ecological study was carried out to determine AD mortality, depression hospitalization and its health service cost of elderly people ( $\geq 60$ years old). All data used in the analysis were obtained from databank provided by SUS (DATASUS) maintained with government information of Brazil Health Ministry.

\section{Ad and suicide mortality trend analysis}

The $\mathrm{AD}$ and suicide mortality trend in Brazilian elderly were performed considering 1996 to 2015 years. In this period all death causes were classified according International Code of Diseases, ICD10 making it possible to compare them over time. In the analysis, are included two years that mark important events in mental health care in Brazil. In 2001 BPR was approved and in 2011 was implanted Psychological Care Network which manages all services related to mental health in Brazil. To perform these analysis, data were obtained from Brazilian Mortality Information (SIM) coordinated by Department of Health Analysis Situation of Secretariat of Health Surveillance, Brazilian Health Ministry together with the States and Cities Health Secretariats. In this study were analyzed number of deaths counted according to the place of residence of the deceased. AD mortality causes are group in the F30-39 ICD-10 classification that includes follow psychiatric diseases: manic episodes (F30), bipolar disorder (F31), depressive episodes (F32), depressive recurrent disorders (F33), humor disorders (F34), affective mood persistent disorders (F34) and other affective humor disorders (F38). We consider all $\mathrm{AD}$ disorders to analyzed mortality trend since depressive symptoms are present in most of these morbidities. Furthermore, sometimes is not possible to perform an accurate psychiatric diagnosis in elderly people due presence of comorbidities and other intervenient variables. Co-varieties influence on $\mathrm{AD}$ and suicide mortality include sex, and three elderly age group: 60 to $69 ; 70$ to 79 and $\geq 80$ years.

\section{AD morbidity analysis}

Brazilian elderly morbidity presenting AD diagnosis was evaluated by hospitalization trend considering data from 2009 to 2016 period, since this period presented all governmental evaluable data to conduct epidemiological analysis. From BPR law, psychiatric hospitalizations is limited to general hospitals and just when occur critical psychiatric conditions of patients, which can mean a threat to the patient's own life or to the lives of others. In other words, at principle there is no long-term hospitalization in Brazil for mental health patients. Therefore, analysis of elderly AD hospitalizations could be considered an indicator of this psychiatric problem. To conduct this analysis, morbidities data were obtained from the Hospital Information System of SUS-SIH/SUS, managed by the Ministry of Health, through the Department of Health Care, together with the State Health Secretariats and the Municipal Health Secretariats, being processed by DATASUS - Department of Informatics of the SUS, of the Executive Secretariat of the Ministry of Health. The hospital units participating in the SUS (public or private agreement) send the information of hospitalizations made through the IAH - Authorization for hospital admission, for municipal managers (if in full management) or state (for others). This information is consolidated in DATASUS, forming a valuable database, containing data of most of the hospitalizations performed in Brazil. Outpatient care costs were also obtained from this same databank information. However, the period analyzed was shorter (2009 to 2016) than AD and suicide-mortality analysis, since just from 2008 these data are available for analysis.

\section{Statistical analysis}

Epidemiological data were organized in Excel program datasheet. Annual total number of deaths in $\geq 60$ years was included for the analysis of mortality trends. Trends were analyzed here using Jointpoint regression analysis using free software developed by Surveillance Research Program, National Cancer Institute (USA) that is also use to analyse trends by other mortality causes. The tests of significance use a Monte Carlo Permutation method. The models may incorporate estimated variation for each point (e.g. when the responses are age adjusted rates) or use a Poisson model of variation. In addition, the models may also be linear on the log of the response (e.g. for calculating annual percentage rate change). In Joint point regression the jump model and comparability ratio model provide a direct estimation of trend data where there is a coding change, which causes a "jump" in the rates, but is assumed not to affect the underlying trend. The software automatically locates the discontinuity or "jump" halfway between this last data point and the next one. ${ }^{8}$ This analysis can be use to evaluate the effect of regulatory action by health services as performed by Wheeler et al. ${ }^{9}$ that performed an ecological study to analyse the impact on the incidence of suicide and non-fatal self-harm of regulatory action in 2003 to restrict the use of selective serotonin reuptake inhibitors (SSRIs) in under 18s.

\section{Results}

Figure 1 presents general $\mathrm{AD}$ and suicide trends for Brazilian elderly according sex and age-group. Total AD mortality rate was low and slightly higher in women (1.2/100.000) than men (1.0/100.000). On the other hand, total suicide mortality rate was higher in men $(13.5 / 100.000)$ than females $(2.5 / 100.000)$. In both mortality causes, occurrence was age-dependent, with higher rates in oldest-old group ( $\geq 80$ years), intermediary rates in 70 to 79 years and lower rates with elderly 60-69 years old.

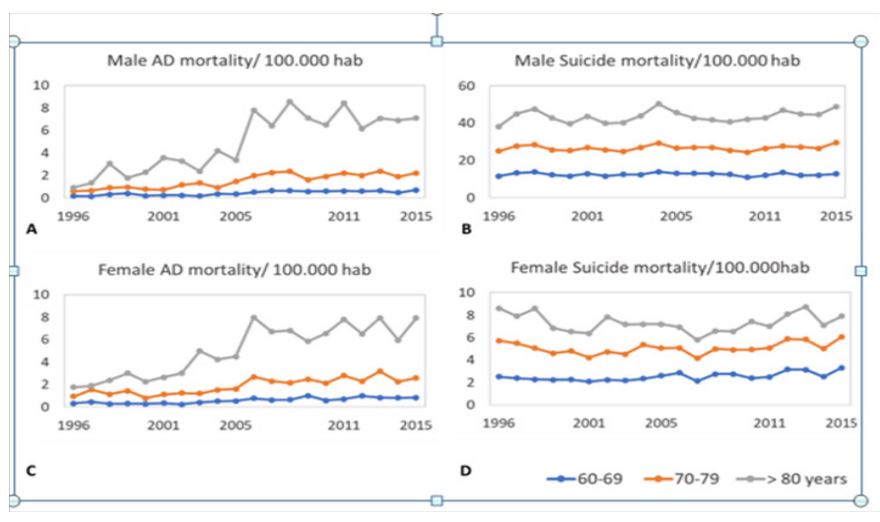

Figure 1 Trends of mortality by AD and suicide in Brazilian elderly people (/100.000 hab) in the period of 1996 to 2015. 
Table 1 shows a synthesis of main data of $\mathrm{AD}$ and suicide mortality analysis, describing annual percentage change (APC) and regression significance data according sex and age-groups. In males, $\mathrm{AD}$ mortality trend did not change significantly among period analysed here (Figure 2). At contrary, females with 60 to 79 years presented a significant linear increase in $\mathrm{AD}$ mortality frequency with an Table I Annual percentage chance (APC) and statistical data of Brazilian elderly affective disorders (AD) and suicide mortality, by sex and age-group in I9962015 period

\begin{tabular}{|c|c|c|c|c|c|}
\hline \multirow[t]{2}{*}{ Sex } & \multirow{2}{*}{$\begin{array}{c}\text { Age-group } \\
\text { (years) }\end{array}$} & \multicolumn{2}{|c|}{ APC } & \multicolumn{2}{|c|}{ Regression data } \\
\hline & & Period & Value & Equation & $\mathrm{p}$ value \\
\hline \multirow[t]{3}{*}{ AD-Male } & $60-69$ & $1996-2015$ & -0.1 & $Y=4.5 I-0.0009 x$ & 0.378784 \\
\hline & $70-79$ & $1996-2015$ & 0.54 & $Y=-8.10+0.005 x$ & 0.053468 \\
\hline & $>80$ & $1996-2015$ & 0.73 & $Y=-11.74+0.007 x$ & 0.111706 \\
\hline \multirow[t]{4}{*}{ AD-Female } & $60-69$ & $1996-2015$ & $6.29 *$ & $Y=-122.97+0.063 x$ & 0.000007 \\
\hline & $70-79$ & $1996-2015$ & $4.87^{*}$ & $Y=-95.1+0.054 x$ & 0.00026 \\
\hline & $>80$ & $1996-2006$ & 19.* & $Y=-349.06+0.74 x$ & 0.000314 \\
\hline & & $2006-2015$ & 0.55 & $Y=-9.57+0.0055 x$ & 0.771058 \\
\hline \multirow[t]{3}{*}{ Suicide-Male } & $60-69$ & $1996-2015$ & -0.1 & $Y=4.5 \mathrm{I}-0.00099 x$ & 0.695546 \\
\hline & $70-79$ & $1996-2015$ & 0.1 & $Y=-8.10+00053 x$ & 0.053468 \\
\hline & $>80$ & $1996-2015$ & 0.73 & $\begin{array}{c}Y=-11.74+ \\
0.0072 x\end{array}$ & 0.111706 \\
\hline \multirow[t]{4}{*}{ Suicide-Female } & $60-69$ & $1996-2015$ & $1.75^{*}$ & $Y=-33.79+0.017 x$ & 0.000675 \\
\hline & $70-79$ & $1996-2007$ & $-2.79 *$ & $Y=57.578-0.028$ & 0.002757 \\
\hline & & $2007-2015$ & $3.48 *$ & $Y=-67.85+0.034$ & 0.006248 \\
\hline & $>80$ & $1996-2015$ & -1.24 & $Y=25.80-0.012$ & 0.162679 \\
\hline
\end{tabular}

*Indicates that the Annual Percentage change (APC) is significantly different from zero at alpha $=0.05$ level

In relation to suicide mortality trends, males showed stable and higher rates without significant changes (Figure 2). On the other hand, females aged with 60-69 years increased significantly suicide mortality rates. Females aged with $70-79$ presents change in their suicide mortality pattern. From 1996 to 2007 suicide rates decreased significantly. However, from 2007 to 2015, the curve reversed, with a significant increase in these deaths (Figure 3). Similar to men, oldestold women $(\geq 80$ years) presented higher and no change suicide mortality rates.

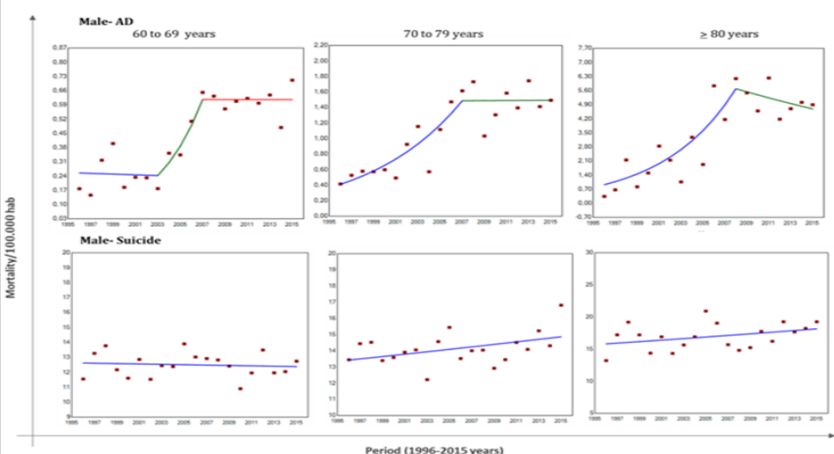

Figure 2 Affective disorders (AD) and Suicide mortality of Males Brazilian elderly people (>60 years old) during 1996-20I5 period. Graphics show regression curves (blue line) and Jointpoints periods where occur significant $(p<0.05)$ changes in the mortality curves represented by different collors (green and red lines). Brown squares represent mortality/100.000 habitants observed from data. estimated $5.58 \%$ increment in AD deaths by year. Oldest-old females follow similar tendency of AD increase mortality until 2006, with higher APC value (near to $20 \%$ by year). However, from 2006 to 2015 this trend stabilized, even though AD mortality rates remained higher than observed in younger women (Figure 3 ). 
$\pm 0.03 / 1000$ hospitalizations). Complementary analysis showed nochanging pattern in this frequency in the period analysed here (Figure $4 \mathrm{~A}$ ). Other variable analysed is respect to mean time (days) that $\mathrm{AD}$ patients remained in the hospital. Again, elderly grouped to 60-69 years presented higher mean time of hospitalization than other $\mathrm{AD}$ subjects. However, in general mean times of hospitalization present a trend to decrease from 2012 year (Figure 4B).

Hospitalization mortality rate was also compared among $\mathrm{AD}$ elderly with different age groups. As expected older-group $(>80$ years) presented higher mortality rate frequency than younger elderly. Among 2010 to 2012 occurred increase in the mortality frequency with elderly $\geq 80$ years (Figure 4 C).

After a brief decline in this frequency, that occur in 2013 year, this indicator started to rise again (Figure 4C). A complementary comparison was performed between all-causes and AD-hospital mortality rate. As can see in Fig. 5D both death groups showed trend to increase according to age, despite the hospital mortality rate to be lower in $\mathrm{AD}$-group than all-cases group.

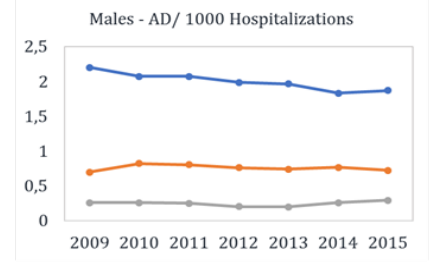

A

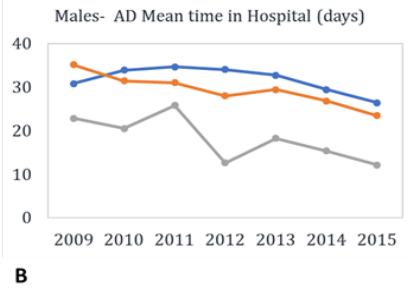

Male - AD Hospital Mortality Rate

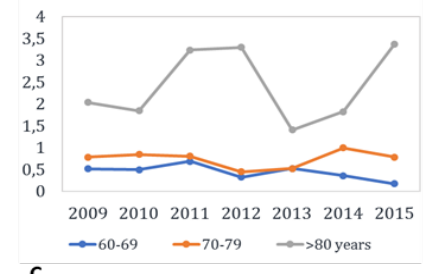

C $\rightarrow 60-69 \rightarrow 70-79 \rightarrow 80$ years

Figure 4 Affective disorders (AD) morbidities (hospitalization) indicators in Brazilian elderly men with different ages.

In females, AD-hospitalization frequency presented a similar pattern observed in elderly males, with higher number of ADhospitalization concentred in elderly aged among 60 to 69 years (Figure 5A).

Mean time (in days) than elderly females remained in the hospital was influenced by age just from 2013 year that older females started to remain more time hospitalized than younger female (Figure 5B). Comparison between hospital mortality rates in the period analysed showed similar results found to elderly males, trending to increase according age (Figure 5C). Other information about this variable is respect that hospital mortality rate in the period analysed here was higher in men $(11.76 \pm 1.19 / 100.000$ hospitalizations) than females (10.93 $\pm 0.90 / 100.000$ hospitalizations) (Figure 5D).

Health cost indicators were also analysed of Brazilian elderly ADdiagnosed in the period of 2009 to 2016. Considering large similarity in the values found to males and females, we opted to present these data jointed information obtained for each sex (Figure 6). Economic costs of $\mathrm{AD}$ hospitalization were initially evaluating considering \% of these cost in relation to cost of hospitalization for all-diagnosed causes. In general, AD-hospitalization costs represented $0,25 \pm 0.05 \%$ of all costs. Most cost were spent with $\mathrm{AD}$-older patients ( $\geq 80$ years) trended to decreased from 2012 year (Figure 6A). Mean value for each hospitalization (in U\$ dollar) is presented in Figure 6B. As can see this value was similar among different age-groups and trended to decrease from 2011 year. Another analysis from these data showed that mean value of each hospitalization trend to be similar between AD-patients and patients hospitalized by all-diagnosed causes (Figure 6C). In both groups values trend to decrease in the period investigated mainly in older patients ( $\geq 80$ years-old) (Figure 6D).

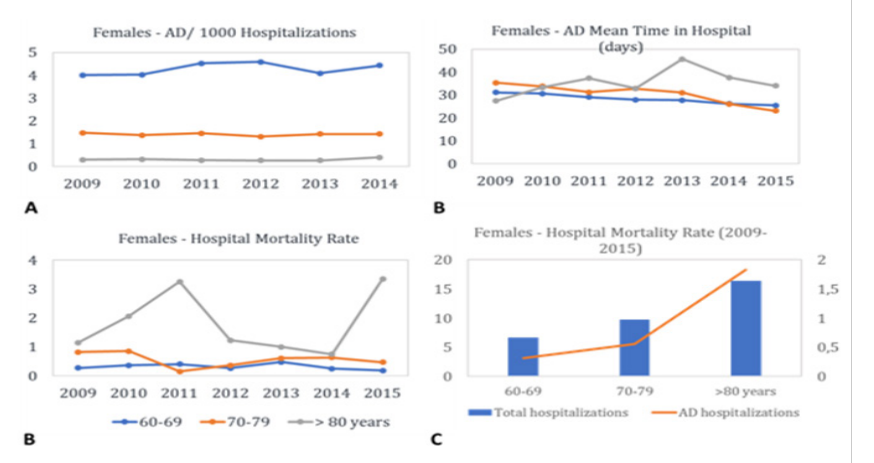

Figure 5 Affective disorders (AD) morbidities (hospitalization) indicators in Brazilian elderly women with different ages.

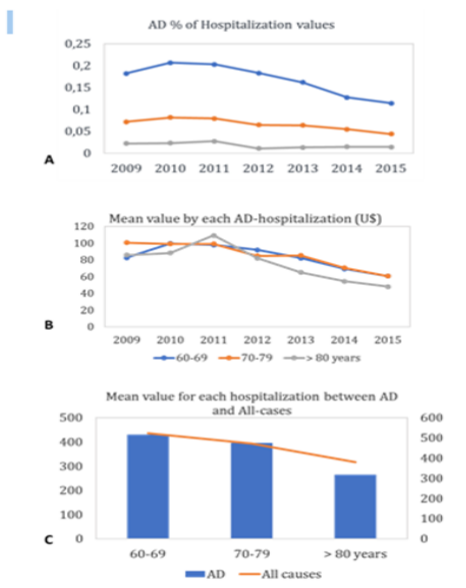

Figure 6 Economical cost indicators related to AD-elderly hospitalizations among 2009 to 2015 years.

\section{Discussion}

The present investigation performed a socio-ecological trend analysis of Brazilian elderly AD mortality, also considering suicide mortality that is an important mental health condition. Additionally, some morbidity indicators in AD elderly patients were also evaluated, as well as, associated-hospitalization costs. AD-mortality presented similar trend between males and females, whereas number suicides in 
elderly males was consistently higher that females. In both mortality causes, older subjects ( $\geq 80$ years old) presented higher mortality rates. Trends in these mortality rates trend to change in some situations, as well as morbidity indicators suggesting influence of health services actions related to management of these psychiatric morbidities. Therefore, it is important to discuss these points to evaluate potential impact of BPR on elderly population that present some AD clinically diagnosed or some psychiatric condition that cause suicide death.

$\mathrm{AD}$ diseases have important role in the elderly health and life quality, since depressive states including major depression has been associated with morbi-mortality in this age-group. However is not easy to evaluate general impact of depression on elderly mortality considering socio-ecological data. This reason of difficulty is related to fact that depression or depressive states associated with other psychiatric disorders can be considered a heterogeneous syndrome. Furthermore, effect psychological and somatic symptoms can be highly variable. An analysis of a sample of patients identified 1030 different profile symptoms in elderly subjects according diagnosed DSM-V criteria. ${ }^{10}$ For this reason, we opted to include in our mortality analysis elderly clinically diagnosed by some AD conditions included in the F30-39 ICD-10 classification. It is important to comment that, due lower number of elderly that mortality cause is considered some $\mathrm{AD}$ condition, we are not able to find large number of ecological studies involving similar analysis. On the other hand, there are great number of studies about suicide and suicide attempt in elderly population, including previous Brazilian investigations. ${ }^{11-15}$

Considering AD trends mortality analyzed here, is important to point out that population-based studies have demonstrated that over $8 \%$ of community-dwelling older people aged 50 years and over have clinically relevant depressive symptoms. ${ }^{16}$ This prevalence is higher if is considered elderly $\geq 70$ years old..$^{17}$ A cross-sectional study performed in 49,025 Brazilian adult subjects showed that 9.7\% presented some degree of depressive symptoms and $3.9 \%$ had major depression. However, despite authors performed an age-correction of these values $\mathrm{AD}$ prevalence on elderly population was not specifically studied. ${ }^{18}$ In fact, nowadays is well established that depression and depressive states are related to poor prognosis of other somatic and metabolic diseases including cardiovascular morbidities. ${ }^{19}$ Depression as also closely related to cognitive decline, dementia and frailty in the elderly population. ${ }^{20}$

For this reason, we consider that mortality evaluation by ADcause could be "the tip of iceberg" and did not represent all extension of mortality impact of this psychiatric disease on elderly mortality. Even so, as the diagnosis of mortality by mental health conditions has been improved in Brazil analysis of AD mortality trends could be considered relevant. Data analysis performed here showed an interesting trend in the elderly mortality by $\mathrm{AD}$ and suicide causes. Clearly, older elderly died by AD and suicide more frequently than younger elderly population. However, whereas suicide deaths presented higher and stable frequency in the period analyzed, deaths by $\mathrm{AD}$-causes trend to increase in $\geq 80$ years subjects, and this trend was similar between males and females. However, morbidities indicators showed that younger elderly were more frequently hospitalized than older subjects, despite frequency of deaths in hospitals to be higher in older group than others.
From these results, two relevant issues could be considered here. First, is respect to increase of AD mortality trends in older subjects ( $\geq 80$ years). Despite the increment in AD-mortality to be potentially related to improvement in the diagnosis of psychiatric mortality causes, prior investigations, as performed by Crumpacker ${ }^{21}$ consider that depression in later life is an important risk factor for death by suicide. Estimative have indicated that almost 800,000 persons die by suicide attempt. ${ }^{22}$ In relation of association between sex and suicide, is well known that its mortality cause is higher in male than females, and therefore, older male could be considered main suicide risk group. In order to explain these important epidemiological gender differences was developed the "concept of male depression" that could present differential and many times no detectable depressive symptoms, that many times are not recognized as depression. ${ }^{23}$ Recent studies about this epidemiological evidence, as performed by Briggs et al ${ }^{24}$ have suggested that maintenance of suicide rates in older subjects could be associated to significant proportion of undetected or untreated cases of $\mathrm{AD}$, especially depression.

The maintenance of high frequency of suicide in very older elderly is not universal and is potentially reversible. For example, studies such as developed by Shah et al. ${ }^{25}$ estimated a suicide decline in later life, suicide rates remain high in older people. ${ }^{25}$ Therefore, suicide rates found in Brazilian elderly $\geq 80$ years could be treated as important public health with specific preventive program with aim could be prevent suicide attempt.

However, as is commented by Briggs et al. ${ }^{24}$ interventions aimed at improving detection and treatment of depression and suicidal behavior in later life need to be targeted at several different levels. On the other words, these programs could be more specific considering the impact of complex social, biological, functional and health factors that act on elderly behavior leading to suicide attempt. In this respect, authors comment that if public awareness campaigns have been successful in reducing the stigma around mental health conditions in younger people, similar efforts are required to focus on later life subjects with suicide risk. From our results, we also suggest that, in elderly population these programs could extend their action to prevent concomitantly suicide and AD diseases.

Considering the specific Brazil context, Joint point regression curve analysis of $\mathrm{AD}$ and suicide mortality performed here suggest that current health services constructed to attend BPR law did not present affective actions to decrease mortality and morbidities indicators of AD elderly subjects. This because, despite to be occurred a decrease in the frequency of AD hospitalizations, mainly from 2012 year, as well as in the period of hospitalization (in days) and in the hospitalization costs, in general the number of $\mathrm{AD}$ and suicide deaths did not consistently decrease in the period analyzed here. Considering that exist a very good structure of mental health services belong to Brazilian Psychological Care Network, efforts to improve specific attention to elderly subjects could be constructed in the next years. Similar to other risk factors to chronic non-transmissible diseases, such as glucose to screening diabetes mellitus type 2, blood pressure, waist circumference, cholesterol levels to screening cardiovascular diseases, mammography to screening breast cancer risk, a program of $\mathrm{AD}$ detection in basic health units would be feasible through of trained nurse professionals in use of tools to identify possible 
depressive symptoms. There are several easy and ship instruments, such as geriatric depressive scale (GDS) that could to identify potential depressive and suicide elderly people. In this context, present study could be use as base to develop intervention investigations related to detection of $\mathrm{AD}$ and suicide ideation on elderly group. Furthermore, this initiative could have some economic impact in the hospitalizations and cost of these services.

Finally, it is important to comment that there are some methodological limitations to our study that must be noted: (1) this is a socio-ecological study, therefore we don't know the exact context that AD deaths were determined; (2) some important variables are risk to $\mathrm{AD}$ and suicide mortality, such as education level, marital status and presence of comorbidities and frailty. Despite for some variables analyzed here we have data of educational and marital status; we opted to focus just sex and age as co-variable due a high Brazilian cultural, social and environmental heterogeneity. Therefore, complementary studies to evaluate influence of these and other social variables in $\mathrm{AD}$ and suicide mortality trends of Brazilian elderly, needs to be performed from future investigations.

\section{Acknoweledgements}

None.

\section{Conflict of interest}

Authors declare that there are no conflicts of interest.

\section{References}

1. Whiteford HA, Degenhardt L, Rehm J, et al. Global burden of disease attributable to mental and substance use disorders: findings from the Global Burden of Disease Study 2010. The Lancet. 2013;382(9904):1575-1586.

2. Katon W, Unützer J, Fan MY, et al. Cost-Effectiveness and Net Benefit of Enhanced Treatment of Depression for Older Adults With Diabetes and Depression. Diabetes Cares. 2006;29(2):265-270.

3. Ozaki Y, Sposito APB, Bueno DRS, et al. Depression and chronic diseases in the elderly. Rev Soc Bras Clin Med. 2015;13(2):149-153.

4. Daskalopoulou M, George J, Walters K, et al. Depression as a Risk Factor for the Initial Presentation of Twelve Cardiac, Cerebrovascular, and Peripheral Arterial Diseases: Data Linkage Study of 1.9 Million Women and Men. PLoS ONE. 2015;11(4):e0153838.

5. Kok RM, Reynolds CF. Management of Depression in Older Adults: A Review. JAMA. 2017;317(20):2114-2122.

6. Lutz J, Fiske A. Functional disability and suicidal behavior in middleaged and older adults: A systematic critical review. J Affect Disord. 2018;227:26-271

7. Garcia LP, Duarte E. Epidemiology and Health Services: the trajectory of the Brazilian National Health System Journal. Cien Saude Colet. 2015;20(7):2081-2090.

8. Kim HJ, Fay MP, Feuer EJ, et al. Permutation tests for join point regression with applications to cancer rates. Statistics in Medicine. 2000;19(3):335-351.
9. Wheeler BW, Gunnell D, Metcalfe C, et al. The population impact on incidence of suicide and non-fatal self harm of regulatory action against the use of selective serotonin reuptake inhibitors in under $18 \mathrm{~s}$ in the United Kingdom: ecological study. BMJ. 2008;336:542.

10. Fried EI, Neese, RM. Depression is not a consistent syndrome: An investigation of unique symptom patterns in the STAR*D study. $J$ Affect Disord. 2015;172:96-102.

11. Minayo MCD, Cavalcante FG. Suicide in elderly people: a literature review. Rev Saúde Pública. 2010;44(4):750-7.

12. Silva PADSD, Rocha SV, Santos LB, et al. The prevalence of common mental disorders and associated factors among the elderly in a Brazilian city. Cien Saude Colet. 2018;23(2):639-646.

13. McMinn B, Booth A, Grist E, et al. Falls and fall injury in mental health inpatient units for older people. Aust Nurs Midwifery J. 2016;24(5):26-9.

14. Hölzel LP1, Härter M, Hüll M. Multiprofessional outpatient psychosocial treatment for elderly patients with mental disorders. Nervenarzt. 2017;88(11):1227-1233.

15. De Jonge, P. Wardenaar KJ, Hoenders HR, et al. Complementary and alternative medicine contacts by persons with mental disorders in 25 countries: results from the World Mental Health Surveys. Epidemiol Psychiatr Sci. 2017;28:1-16.

16. O'regan C, Patricia MK, Hilary $\mathrm{C}$, et al. Oscillometric measure of blood pressure detects association between orthostatic hypotension and depression in population based study of older adults. BMC Psychiatry. 2013;13:266.

17. Steffens DC, Fisher GG, Langa KM, et al. Prevalence of depression among older Americans: the Aging, Demographics and Memory Study. Int Psychogeriatr. 2009;21:879-888.

18. Barros MBA, Lima MG, Azevedo RCS, et al. Depressão e comportamentos de saúde em adultos brasileiros - PNS 2013. Rev Saude Publica. 2017;51:1-8

19. Zhang Y, Chen Y, Ma L. Depression and cardiovascular disease in elderly: Current understanding. J Clin Neurosci. 2018;47:1-5.

20. Vaughan L, Corbin AL, Goveas JS. Depression and frailty in later life: a systematic review. Clin Interv Aging. 2015;10:1947-1958.

21. Crumpacker DW. Suicidality and Antidepressants in the Elderly. Proc (Bayl Univ Med Cent). 2017;21:373-377.

22. Värnik P, Sisask M, Värnik A, et al. Validity of suicide statistics in Europe in relation to undetermined deaths: developing the 2-20 benchmark. Inj Prev. 2012;18(5):321-5.

23. Krumm S, Checchia C, Koesters M, et al. Men's Views on Depression: A Systematic Review and Metasynthesis of Qualitative Research. Psychopathology. 2017;50(2):107-124.

24. Briggs W. The mental health problems and needs of older people following lower-limb amputation. Rev Clin Gerontol. 2006; 16:155-163.

25. Shah A, Raci B, Diego D, et al. Suicide rates in five-year age-bands after the age of 60 years: the international landscape. Aging Ment Health. 2016;20(2):131-138 